\title{
COMAPARTIVE ANALYSIS OF RENEWABLE ENERGY RESOURCES POTENTIALLY ACCESSIBLE IN RURAL AREAS
}

\author{
Elzbieta Szafranko \\ University of Warmia and Mazury in Olsztyn, Poland \\ elasz@uwm.edu.pl
}

\begin{abstract}
Energy in rural areas is needed both for residents and for the purpose of servicing agricultural production. The main sources of energy are large plants, such as heating plants and power plants. However, alternative energy sources, such as wind, solar or bio-energy have become increasingly popular in recent years. In the years 2007 - 2009, the level of energy use from renewable energy sources in the world remains at the level of $17 \%$, in the EU countries $16 \%$, in Poland at the level of $6 \%$. Share of renewable energy carriers in electricity production in 2014 in Poland, by GUS data is as follows: $46.17 \%$ solid biofuels; $38.68 \%$ wind energy; $11.00 \%$ water energy; $4.11 \%$ biogas; $0.035 \%$ solar energy; $0.005 \%$ other. The interest in using energy from these sources is related to the ever-growing demand for energy and the awareness of the threat of depletion of natural energy deposits. Another problem related to generation of energy in a conventional manner is the postproduction waste and pollution associated with these processes, such as sulphur dioxides, nitrogen, coal and dust, which pose a huge threat to the natural environment. Alternative solutions limit the amount of this waste. The purpose of the research presented in the article is to present a complicated preparatory procedure related to implementation of facilities of this type and the possibility of their use in rural areas. The research included an analysis of sample investments, review of documentation and a library query. As a result of the research and analysis, a number of requirements related to preparation and implementation of investments in renewable energy sources were indicated. The construction of a wind or water power plant is a much more serious undertaking than, for example, a biogas plant and therefore the preparatory activities take a lot more time. The largest variety of activities can be seen in the conceptual stage preceding the administrative activities. The preparation of the necessary documents is also different, as are the conditions for implementation and subsequent operation. At the end of the analysis, the advantages, disadvantages and features of installations that can be found in rural areas are presented.
\end{abstract}

Keywords: civil engineering, energy, renewable sources, procedures.

\section{Introduction}

Renewable energy resources include non-fossil sources, such as wind power, solar power, geothermal power, hydropower, energy of sea waves, currents and tides, energy generated from biomass, biogas, agricultural biogas and bioliquids. RER can be divided into globally and locally available ones, the latter being accessible in particular countries or regions. The available global energy sources satisfy the condition of ensuring constant power supply in any geographical location. Examples are solar energy in the form of solar radiation or the energy under the Earth's crust. Available local sources are found in specific areas on the Earth. This group is represented by solar energy in the form of heat, kinetic energy of winds, energy from the oceans, sea waves and tides, hot springs and the kinetic energy of rivers [1-3].

It is not uncommon in rural areas to have a limited access to energy generated in big power plants that serve large areas. The problem of securing energy supplies is often aggravated by the shortage of local power plants and power transmission infrastructure [4]. This is just another argument in favour of considering the concept of local facilities which will tap into renewable energy resources. Because of the surrounding conditions, such as small settlements, scattered houses or farmsteads, biogas plants as well as solar or wind power facilities are most often recommended and implemented [5-7].

In order to take the advantage of RER, it is necessary to build facilities equipped with the installations that allow recovery of this energy, its accumulation and conversion into thermal or electric power, which can be then utilised by the domestic economy. For such facilities to be constructed, it is essential to undertake a series of actions, which together compose investment projects. On the one hand, certain undertakings are needed to achieve the previously planned targets. On the other hand, financial inputs are required to satisfy specific needs. The implementation of an investment process entails the performance of numerous actions of different nature. In order to illustrate the above process, several models of investments recommended for implementation in the countryside have been analysed. 


\section{Brief description of the analysed facilities, including a review of the source references and literature}

Our analysis of preparation and implementation of investment projects connected with the use of RER was made on the basis of installations, which are most widespread in rural areas, i.e. a wind farm, solar power plant, and a biogas plant. Examples of such development projects were found in the rural areas of north-eastern Poland. The analysis focused on the tasks carried out at the concept design and investment preparation stage. Having first analysed the documentation, it was concluded that the biggest differences occurred at this stage.

\section{Wind farm}

An investment process involved in the execution of projects consisting of construction of wind farms, compared to other local power generation solutions, is extremely complicated. The reason is that an investor must satisfy several unique formal and legal requirements. The first step in the concept design stage is to select a suitable location. In this case, the attractiveness of a site arises from its wind potential $[8,9]$. Wind velocity is measured in all potential locations, and 'wind velocity maps' are drawn. In view of the future work and maintenance of a windmill, an important measure is the lowest speed of wind at which the wind turbine reaches its nominal value, and the maximum wind power at which the wind turbine switches off [10]. Moreover, when evaluating the available locations, the following criteria are considered: how far they are from human settlements, and what mutual interactions may arise between the planned development and the local nature and economy. Some of these factors have an impact on the assessment procedure of impact of the natural environment [11].

The subsequent step is to make a preliminary analysis of environmental restrictions. At this stage, it is verified whether the shortlisted sites are not subject to one of the forms of natural environment protection. Construction of a wind farm belongs to the group of development plans, for which it is mandatory to obtain a decision about environmental conditions. It is also required to take into account the participation of the local population in a procedure to the evaluation of the submitted development plan. At this stage, it is obligatory that local authorities as well as local society be consulted, and educational actions be undertaken in order to inform local communities about the benefits gained from the planned investment project [8-11].

\section{Biogas plant}

Preparation of an investment consisting of a biogas production and utilisation plant, owing to its specific character, differs from the previous procedure, although it also requires specialist knowledge. Same as above, the concept design stage is significant. At this step, it is important to analyse all available solutions in terms of their technical, organisational and economic feasibility, so as to minimise the investment risk and achieve the optimal efficiency [12;13].

In the early stage, an analysis of all potential feedstocks should be made, including their availability, constant supply and biogas productivity. It is essential to check the quantities of locally available energy resources and their transportability. This analysis contributes to the decision on the localisation of a planned facility. The localisation decision should also include an assessment of possible connection of the biogas plant to electric power transmission or gas distribution grid, and a statement of the conditions for connection issued by the regional electric power or gas company, as well as a connection to public roads $[12 ; 13]$. An analysis of the infrastructural conditions typically comprises accessibility of the electric power grid, gas grid, waterworks and sewers, assessment of possibilities of heat transmission, and the utilities available on the land plot to be developed.

Agricultural biogas plants over 0.5 MW are classified as investment developments, which may potentially have a considerable influence on the natural environment, which is why the investor is obligated to proceed through a complete procedure of environmental impact assessment. A preliminary choice of a site on which a biogas plant will be built should consider, for example, the distance to residential houses and the restrictions imposed to protect the environment and nature. An interesting component of preliminary evaluation is an analysis of technological options, such as types of feedstocks, and technical processes and lines $[14 ; 15 ; 18]$. 


\section{Solar power plant}

Elements of a solar power plant typically comprise a supporting structure, composed of aluminium, steel or composite pipe framework seated directly on the ground, on which photovoltaic panels and low voltage cable connections to a nearby transformer station are mounted. The main goal of this type of development is to generate electric power during the daytime, from solar radiation, and to transmit it to a transformer station. When searching for the right location, it is crucial to consider the accessibility of a land parcel and the transportability of elements assembled during the construction. It is equally important to ensure if there is a valid local spatial management plan covering the chosen land plot, if the planned construction requires a building permit [16-18].

Solar power generation employs technologies with the least impact on the environment among all RER. It does not emit harmful substances and noxious odours to the atmosphere, it does not generate noise, and it does not constitute an obstacle to migrating animals. Therefore, solar energy plants can be situated in locations where other solutions are unacceptable. The impact that a solar power plant has on the natural environment occurs mostly during its construction, when elements of the supporting structure, equipment, photovoltaic panels and other necessary materials must be transported; afterwards, the scaffolding elements must be driven into the ground in order to assemble the structure, panels and all other equipment must be mounted and connected to cables [16]. This stage causes a transient increase in the emission of exhaust fumes and dust, as well as a higher level of noise due to the construction and assemble work, as well as the vehicles arriving at and moving on the construction site. Pursuant to the environmental impact assessment (EIA) requirements, the society should be involved in the pending environmental decision and the information about the publication of the report should be made public $[17 ; 18]$. Owing to the negligible nuisance caused by solar power plants, they do not usually raise objections among local communities. Moreover, not all of them require a building permit.

\section{The research course and methods}

Specific tasks were set to achieve during the research. The first stage consisted of studying documentation prepared for model investment projects and selecting the objects for further analysis. While identifying the problems connected with preparation of an investment into RER, meetings and interviews with the investors were held. Next, field trips were made to interview the users of the analysed objects. All the data gathered were arranged in information spreadsheets, and all interviews and talks were documented in the form of surveys and questionnaires. The flowchart in Fig. 1 illustrates the research procedure.

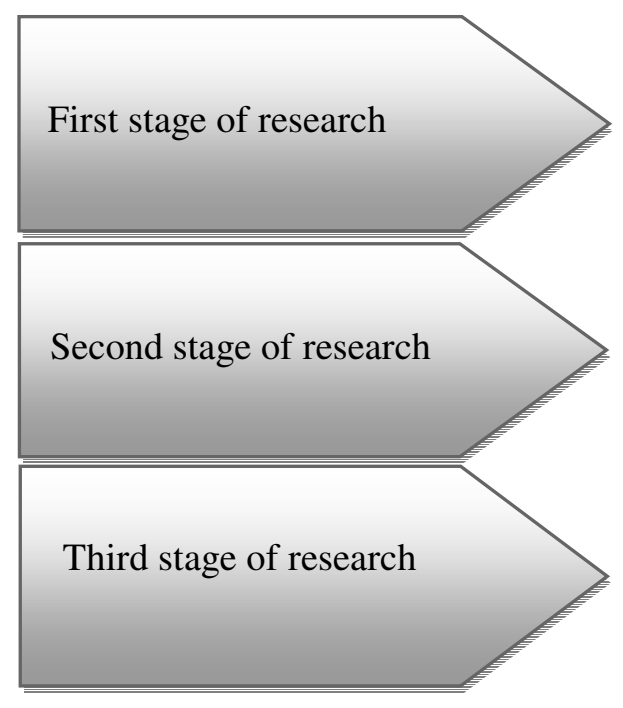

\begin{tabular}{|l|}
\hline - Review of the literature \\
- Overview of source materials \\
- Studying documentation, \\
- Selecting object for further analysis \\
\hline \hline - Identifying problems \\
- Analysis of procedures \\
- Interviews \\
- Surveys and questionnaires \\
\hline \hline - Collection of different data \\
- Analyses of concept phase \\
- Analyses of formal regulations \\
- Comparative analyses and conclusions \\
\hline \hline
\end{tabular}

Fig. 1. Research procedure 


\section{Research results}

In order to summarise the research covering the concept design phase and the binding formal and legal procedures for the investment projects described herein, a comparative analysis was made. Table 1 presents the most important steps.

The comparison of the basic information pertaining to the implementation of RER investment projects has demonstrated that the major differences mostly occur at the stage of preparation for the execution of a development plan. This stage involves numerous concept-design activities which are not regulated by law. Processing records about wind power or identifying environmental restrictions are examples of problems, which may arise due to the specific character of a given development project and its localisation. Each of the investments described in this paper requires a different set of analyses, more or less time consuming. To illustrate this question, a detailed analysis of model investments was conducted. Table 2 shows how much time it takes to perform analyses and make decisions before a building permit can be obtained.

Table 1

\section{Comparative specification of described investments}

\begin{tabular}{|c|c|c|}
\hline $\begin{array}{c}\text { Invest- } \\
\text { ment }\end{array}$ & Concept design & Formal and legal matters \\
\hline 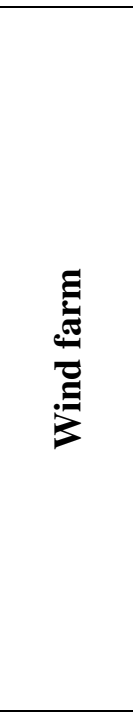 & $\begin{array}{l}\text { 1. Choice of a location. } \\
\text { 2. Preliminary analysis of windiness. } \\
\text { 3. Analysis of environmental } \\
\text { restrictions. } \\
\text { 4. Analysis of infrastructural } \\
\text { conditions. } \\
\text { 5. Analysis of social circumstances. }\end{array}$ & $\begin{array}{l}\text { 1. Studying the local spatial management } \\
\text { plan (if there is one). } \\
\text { 2. Procedure of changing the spatial } \\
\text { management plan (if it does not envisage } \\
\text { the location of a RER investment } \\
\text { construction). } \\
\text { 3. Acquiring the right to the land parcel. } \\
\text { 4. Making an environmental impact } \\
\text { assessment. } \\
\text { 5. Obtaining an environmental decision. } \\
\text { 6. Obtaining a statement of conditions for } \\
\text { connection to a grid. } \\
\text { 7. Obtaining a decision on the Conditions of } \\
\text { 8. Making a building design for a wind farm. } \\
\text { 9. Obtaining a building permit. }\end{array}$ \\
\hline 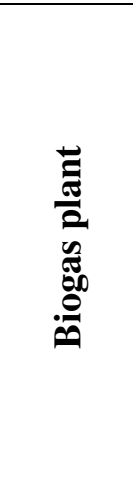 & $\begin{array}{l}\text { 1. } \text { Choice of a location. } \\
\text { 2. Analysis of possible feedtsock } \\
\text { supplies. } \\
\text { 3. Analysis of infrastructural } \\
\text { conditions. } \\
\text { 4. Analysis of environmental } \\
\text { restrictions. } \\
\text { 5. Analysis of technological options. } \\
\text { 6. Analysis of social circumstances. } \\
\text { 7. Feasibility study (for large biogas } \\
\text { plants). }\end{array}$ & $\begin{array}{l}\text { 1. Choice of a legal form of the investment } \\
\text { plan. } \\
\text { 2. Signing contracts for feedstock deliveries. } \\
\text { 3. Obtaining an environmental decision. } \\
\text { 4. Obtaining a decision on the Conditions of } \\
\text { Land Development and Management. } \\
\text { 5. Acquiring the right to the land parcel. } \\
\text { 7. Preparing a building design. } \\
\text { 7. Obtaining a building permit. }\end{array}$ \\
\hline 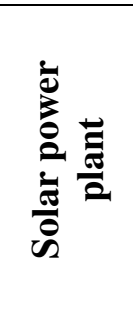 & $\begin{array}{l}\text { 1. Choice of a location. } \\
\text { 2. Verification of the spatial } \\
\text { management plan (if a building } \\
\text { permit is mandatory). } \\
\text { 3. Analysis of social circumstances. }\end{array}$ & $\begin{array}{l}\text { 1. Acquiring the right to the land parcel. } \\
\text { 2. Making an environmental impact } \\
\text { assessment. } \\
\text { 3. Obtaining an environmental decision. } \\
\text { 4. Obtaining a 'localisation' decision. } \\
\text { 5. Notification or obtaining a building } \\
\text { permit (if required). }\end{array}$ \\
\hline
\end{tabular}


Time of operation (in months) for preliminary activities for

Table 2 investment projects such as a wind farm and a solar power plant

\begin{tabular}{|l|c|c|}
\hline \multicolumn{1}{|c|}{ Time of operation (in months) } & Wind farm & Solar power plant \\
\hline Preliminary analysis of windiness & 9 & - \\
\hline Studies of environmental restrictions & 2 & - \\
\hline Acceptance of the local community & 5 & - \\
\hline Eco- physiographic documentation & 2 & 2 \\
\hline Environmental decision & 4 & 1 \\
\hline Location decision & 3 & 2 \\
\hline Building permit & 2 & 6 months \\
\hline Total time & 27 months & \\
\hline
\end{tabular}

\section{Summary and conclusions}

Facilities raised to use renewable energy resources are highly varied. Their brief description in this paper indicates what requirements must be met when preparing their construction. Building a wind farm is a much more challenging enterprise than, for example, constructing a solar power plant, which is why the former needs longer preparation time. In the latter case, it is essential to find an adequately large land plot to install solar panels. The highest variation in the activities can be seen at the concept design phase, which precedes the administrative stage. This is due to the specificity of each type of RER facilities, and the lack of legal regulations detailing these steps. Moreover, a different source of energy is intended to be used in each described case, hence, the location of a planned development depends on the accessibility to a particular resource. An analysis of these matters can be so tedious that, for instance, an assessment of winds for the location of a wind farm can take from half a year to a year. Other problems arise from the required EIA or conditions related to the infrastructure.

Conditions specific for a given location and the nature of the RER facilities as such are taken into account. Above all, any undertaking that will be qualified as significantly affecting the environment requires a thorough analysis. For implementation in rural areas, facilities that do not require complicated procedures and can be installed by individual users are recommended.

This research has proved that the best effects and the least problems are generated by the use of solar energy. Solar power plants do not require complicated procedures to be constructed, and do not cause a nuisance during their operation, which is not complicated either. The only foreseeable obstacle is a large area that a solar power plant covers, but it is less of a problem in agricultural areas, where no restrictions have been noted in any of the analysed cases.

\section{References}

[1] Ellabban O., Abu-Rub H., Blaabjerg F. Renewable energy resources: Current status, future prospects and their enabling technology. Renewable and Sustainable Energy Reviews, 39, 2014, pp. 748-764.

[2] Dincer I. Renewable energy and sustainable development: a crucial review. Renewable and sustainable energy reviews, 4(2), 2000, pp. 157-175.

[3] Szafranko E. Selected problems of assessment of suitability of Rural areas for investment activities on an example an optimal location for production plant, In proceedings of the international scientific conference. Engineering for Rural Development Jelgava, 24.-26.05.2017. Latvia University of Agriculture, pp. 1202-1207

[4] Duthie J. M., Whittington H. W. Securing renewable energy supplies through carbon dioxide storage in methanol. In IEEE Power Engineering Society Summer Meeting, Vol. 1, 2002, pp. 145-150). IEEE.

[5] Hahn H., Krautkremer B., Hartmann K., Wachendorf M. Review of concepts for a demand-driven biogas supply for flexible power generation. Renewable and Sustainable Energy Reviews, 29, 2014, pp. 383-393. 
[6] Sharma D. C. Transforming rural lives through decentralized green power. Futures, 39(5), 2007, pp. 583-596.

[7] Brown N. L., Howe J. W. Solar energy for village development. Science, 199(4329), 1978, pp. 651-657.

[8] Gasch R., Twele J. (Eds.). Wind power plants: fundamentals, design, construction and operation. Springer Science \& Business Media, 2011.

[9] Szafranko E. Decision problems in management of construction projects. In IOP Conference Series: Materials Science and Engineering Vol. 251, No. 1, 2017, pp. 012048, IOP Publishing

[10] Jonkman J., Butterfield S., Musial W., Scott G. Definition of a 5-MW reference wind turbine for offshore system development (No. NREL/TP-500-38060). National Renewable Energy Lab.(NREL), Golden, CO (United States), 2009.

[11] Akella A. K., Saini R. P., Sharma M. P. Social, economical and environmental impacts of renewable energy systems. Renewable Energy, 34(2), 2009, pp. 390-396.

[12] Gebrezgabher S. A., Meuwissen M. P., Oude Lansink A. G. Costs of producing biogas at dairy farms in the Netherlands. International Journal on Food System Dynamics, 1, 2010, pp. 1-10.

[13] Szafranko E. Application of multi-criteria methods to an assessment of the localisation of a waste thermal treatment plant. International Multidisciplinary Scientific GeoConference: SGEM: Surveying Geology \& mining Ecology Management, 2, 2016, pp. 65-76.

[14] Nettman E., Bergmann I., Pramschüfer S., Mundt K., Plogsties V., Herrman, C., Klocke M. Polyphasic analyses of methanogenic archaeal communities in agricultural biogas plants. Appl. Environ. Microbiol., 76(8),2010, pp. 2540-2548.

[15] Igliński B., Buczkowski R., Iglińska A., Cichosz M., Piechota G., Kujawski W. Agricultural biogas plants in Poland: Investment process, economical and environmental aspects, biogas potential. Renewable and sustainable energy reviews, 16(7), 2012, pp. 4890-4900.

[16]Zhang H. L., Baeyens J., Degrève J., Cacères G. Concentrated solar power plants: Review and design methodology. Renewable and sustainable energy reviews, 22, 2013, pp. 466-481.

[17] Tsoutsos T., Frantzeskaki N., Gekas V. Environmental impacts from the solar energy technologies. Energy Policy, 33(3), 2005, pp. 289-296.

[18] Ambrus T., Lorant D., Artemyev A., Barczak M., Dombay S. Renewable energy sources, rural development, tourism. In proceedings of the international scientific conference Engineering for Rural Development, Jelgava, Latvia University of Agriculture, pp. 1909-1915, 2018. 